This item was submitted to Loughborough's Research Repository by the author.

Items in Figshare are protected by copyright, with all rights reserved, unless otherwise indicated.

\title{
Chiral counterion strategy in Cu-catalyzed asymmetric allylic oxidation of linear alkenes
}

PLEASE CITE THE PUBLISHED VERSION

http://dx.doi.org/10.1515/asorg-2015-0005

PUBLISHER

De Gruyter Open

VERSION

VoR (Version of Record)

\section{PUBLISHER STATEMENT}

This work is made available according to the conditions of the Creative Commons Attribution-NonCommercialNoDerivatives 3.0 Unported (CC BY-NC-ND 3.0) licence. Full details of this licence are available at: http://creativecommons.org/licenses/by-nc-nd/3.0/

\section{LICENCE}

CC BY-NC-ND 3.0

\section{REPOSITORY RECORD}

Incerti-Pradillos, Celia A., Daniel Hudson, and Andrei V. Malkov. 2019. "Chiral Counterion Strategy in Cucatalyzed Asymmetric Allylic Oxidation of Linear Alkenes”. figshare. https://hdl.handle.net/2134/21319. 


\section{Celia A. Incerti-Pradillos, Daniel Hudson, Andrei V. Malkov*}

\section{Chiral Counterion Strategy in Cu-Catalyzed Asymmetric Allylic Oxidation of Linear Alkenes}

DOI 10.1515/asorg-2015-0005

Received July 14, 2015; accepted July 29, 2015

Abstract: Application of a chiral counter-ion strategy in the Kharasch-Sosnovsky reaction is reported. Copper(I) phosphates obtained from axially chiral, BINOL-derived phosphoric acids were investigated as catalysts in the enantioselective allylic oxidation of acyclic alkenes. Good yields and high regioselectivity towards branched allylic ester have been achieved. The chiral phosphates investigated exhibited modest enantioselectivities.

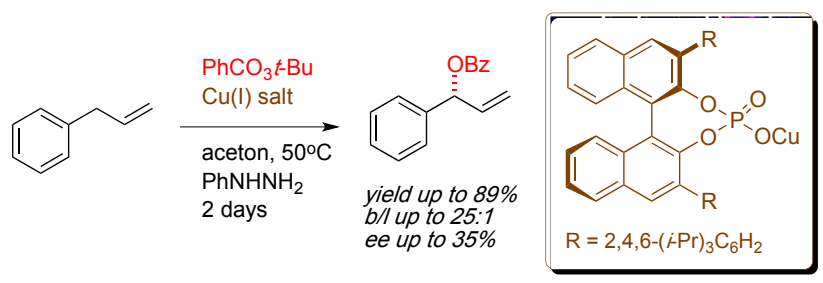

Keywords: allylic oxidation, allylic esters, asymmetric catalysis, chiral counterion, chiral phosphates, regioselectivity

Direct $\mathrm{Cu}$-catalyzed oxidation of allylic $\mathrm{C}$ - $\mathrm{H}$ bonds discovered in 1958 by Kharasch and Sosnovsky [1-3] is an important synthetic transformation that enables a facile conversion of unsaturated hydrocarbon feedstock to valuable functionalized synthetic building blocks. The direct selective functionalization of an $\mathrm{sp}^{3} \mathrm{C}$-H bond is a challenging problem due to the high bond dissociation energy (for methane, $\Delta H_{298}$ $=105 \mathrm{kcal} / \mathrm{mol})$, whereas an allylic $\mathrm{C}-\mathrm{H}$ bond is weaker $\left(\Delta H_{298}\right.$ $=89 \mathrm{kcal} / \mathrm{mol}$ ) due to the resonance stabilization of the allylic radical by the adjacent double bond [4], which is important for exercising control over the reaction.

\footnotetext{
*Corresponding author: Andrei V. Malkov: Department of Chemistry, Loughborough University, Loughborough, Leics., LE11 3TU, UK, E-mail: A.Malkov@lboro.ac.uk

Celia A. Incerti-Pradillos, Daniel Hudson: Department of Chemistry, Loughborough University, Loughborough, Leics., LE11 3TU, UK
}

In the original work by Kharasch and Sosnovsky [2], oxidation of cyclohexene $\mathbf{1}$ and 1-octene $\mathbf{2}$ with tert-butyl peroxybenzoate 3 in the presence of catalytic amounts of $\mathrm{CuBr}$ (Scheme 1) was investigated. Cyclohexene afforded the corresponding allylic benzoate $\mathbf{4}$, while in the case of terminal alkene 2 , selective formation of a branched isomer 5 was observed (5/6 ratio 99:1). The mechanistic aspects of this reaction were later investigated by experimental and theoretical methods [5-12]. As compounds $\mathbf{4}$ and $\mathbf{5}$ feature a stereogenic centre, attempts at the asymmetric variant of this transformation soon followed, though these early efforts met with limited success [13,14]. Development of the enantioselective Kharasch-Sosnovsky reaction gained momentum three decades later with the introduction of chelating nitrogen ligands [15-25], that in some instances exhibited enantioselectivities up to $90 \%$ ee [26-29]. Considerable effort was also directed into optimization of the reaction conditions to make it appealing from a practical point of view [30-35].

.

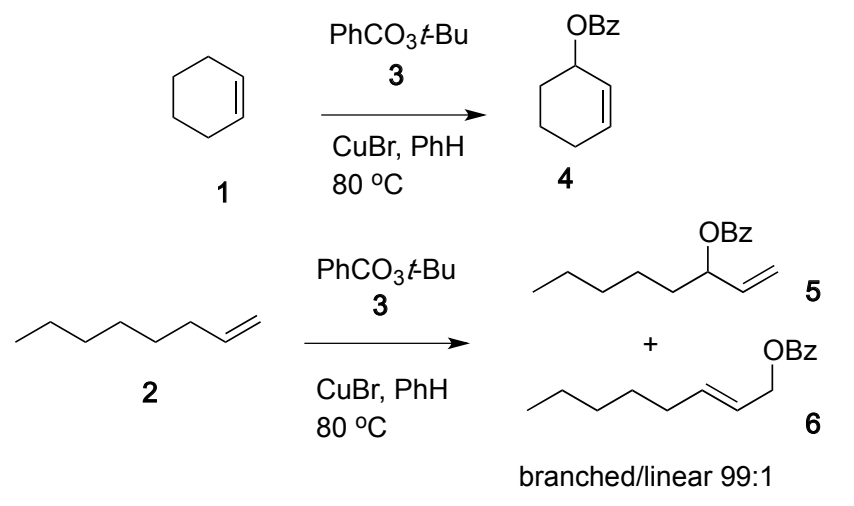

Scheme 1

However, the success of the asymmetric methods is generally limited to cyclic alkenes, whereas enantioselectivity for linear terminal alkenes remains a challenging issue $[16,25,27,36,37]$. Herein, we report on the application of a chiral counter-ion strategy [38-40] to the Kharasch-Sosnovsky reaction. We reasoned that the close proximity of the chiral counterion to the catalytically active metal centre would confer sufficient 
steric bias, leading to enantiodifferentiation in the product formation.

Chiral phosphoric acids and their conjugate bases perform excellently in chiral Brønsted acid catalysis [41,42]. Therefore, their copper salts were investigated as catalysts in a model Kharasch-Sosnovsky reaction, where allylbenzene served as the substrate and tert-butyl peroxybenzoate $\mathbf{3}$ was employed as the stoichiometric oxidant.

A series of chiral $\mathrm{Cu}(\mathrm{I})$ phosphates 10-12 were prepared by heating at reflux $\mathrm{Cu}_{2} \mathrm{O}$ with excess of the appropriate BINOL-derived phosphoric acids 7-9 (acid: $\mathrm{Cu}_{2} \mathrm{O}$ 3:1) in an appropriate anhydrous solvent (Scheme 2). Synthesis of 11 and 12 was carried out in acetonitrile, $\mathrm{Cu}_{2} \mathrm{O}$ fully dissolved in under $3 \mathrm{~h}$ to afford, after removal of solvent, the respective copper salts as pure white solids. Thus prepared salts were stored under inert atmosphere as on exposure to air, they rapidly turned light blue in colour due to oxidation of $\mathrm{Cu}(\mathrm{I})$ to $\mathrm{Cu}(\mathrm{II})$. Phosphoric acid 7 derived from the parent $(R)$-BINOL proved virtually insoluble in acetonitrile, therefore the reaction was carried out in methanol. It was difficult to monitor the end point of the reaction (disappearance of the red $\mathrm{Cu}_{2} \mathrm{O}$ ) as the soluble product formed a deep red solution. Nonetheless, a complete conversion was achieved after 7 days and the resulting salt was obtained after filtration of the reaction mixture and removal of solvent under vacuum.

Initial screening of the reaction conditions was carried out at $0.5 \mathrm{mmol}$ scale in acetone $(1 \mathrm{~mL})$ using tert-butyl peroxybenzoate 3 as the oxidant and a 5-fold excess of allylbenzene $\mathbf{1 3}$ (Table 1). To facilitate analysis of the reaction mixtures including determination of the enantiomeric composition of the products by chiral chromatography, authentic racemic samples of $\mathbf{1 4}$ and $\mathbf{1 5}$ were synthesized by literature methods (see Experimental for details).
First, phosphate $(R)$-10 derived from the parent (R)-BINOL was examined as a catalyst. At room temperature there was no sign of any product formation after 4 days. At $50^{\circ} \mathrm{C}$, some conversion was achieved and the branched isomer 14 was isolated in 18\% yield, but in racemic form. Only traces of the linear isomer 15 were detected by ${ }^{1} \mathrm{H}$ NMR spectroscopy (entry 1 ).

A bulkier catalyst $(S)$-11 under the same conditions demonstrated essentially the sameresults: low reactivity, high regioselectivity towards the branched isomer 14 but negligible enantioselectivity (entry 2). The low reactivity of the catalyst could be affected by oxidation of $\mathrm{Cu}(\mathrm{I})$ species to the inactive $\mathrm{Cu}$ (II) counterparts. To accelerate the reaction, phenylhydrazine was added to reduce $\mathrm{Cu}(\mathrm{II})$ to $\mathrm{Cu}(\mathrm{I})$ in situ $[23,25]$. In the presence of phenylhydrazine, the reaction was complete at room temperature in just 2 days to afford $\mathbf{1 4}$ as the major isomer in 71\% yield, albeit in racemic form (entry 3 ).

Improvement in enantioselectivity was achieved with catalyst 12 derived from TRIP 9. In contrast to phosphoric acid 8, rotation about the $\mathrm{C}-\mathrm{C}$ bond linking the aryl groups to the BINOL core is restricted in the TRIP 9, thus creating an additional steric bias. At $50^{\circ} \mathrm{C}$, in the absence of the reducing reagent the reaction required 4-7 days for completion to afford the branched isomer (14) in up to $18 \%$ ee (entries 4,5 ). In the presence of phenylhydrazine, it took just 2 days to afford ester 14 in high yield (89\%) and improved enantioselectivity (25\%, entry 6). Next, we examined the possibility of preparing the catalyst in situ by mixing $\mathrm{Cu}(\mathrm{OTf})_{2}$, with (R)-TRIP (9) followed by reduction to $\mathrm{Cu}(\mathrm{I})$ with phenylhydrazine, however, this led to a complete loss of enantioselectivity (entry 7). Our attempt at improving enantioselectivity by lowering the reaction temperature was equally unsuccessful (entry 8).<smiles>[R]c1cc2ccccc2c(-c2oc3cc4ccccc4cc([R])c2-3)c1OP(=O)(O)O</smiles>

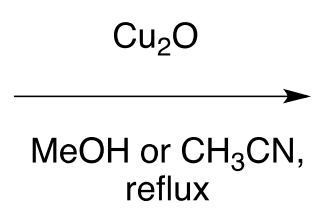

(R)-7, $\mathrm{R}=\mathrm{H}$

(S)-8, $\mathrm{R}=3,5-\left(\mathrm{CF}_{3}\right)_{2} \mathrm{C}_{6} \mathrm{H}_{3}$

(S) $-9, \mathrm{R}=2,4,6-(i-\mathrm{Pr})_{3} \mathrm{C}_{6} \mathrm{H}_{2}$

$(R)-9, \mathrm{R}=2,4,6-(i-\mathrm{Pr})_{3} \mathrm{C}_{6} \mathrm{H}_{2}$<smiles>[R]c1cc(-c2c([R])cc3ccccc3c2OP(=O)(O)OC)c2ccccc2c1</smiles>

(R)-10, $\mathrm{R}=\mathrm{H}$

(S)-11, $\mathrm{R}=3,5-\left(\mathrm{CF}_{3}\right)_{2} \mathrm{C}_{6} \mathrm{H}_{3}$

(S)-12, $\mathrm{R}=2,4,6-(i-\mathrm{Pr})_{3} \mathrm{C}_{6} \mathrm{H}_{2}$

$(R)-12, \mathrm{R}=2,4,6-(i-\mathrm{Pr})_{3} \mathrm{C}_{6} \mathrm{H}_{2}$ 
Table 1. Screening reaction conditions for allylic oxidation ${ }^{a}$
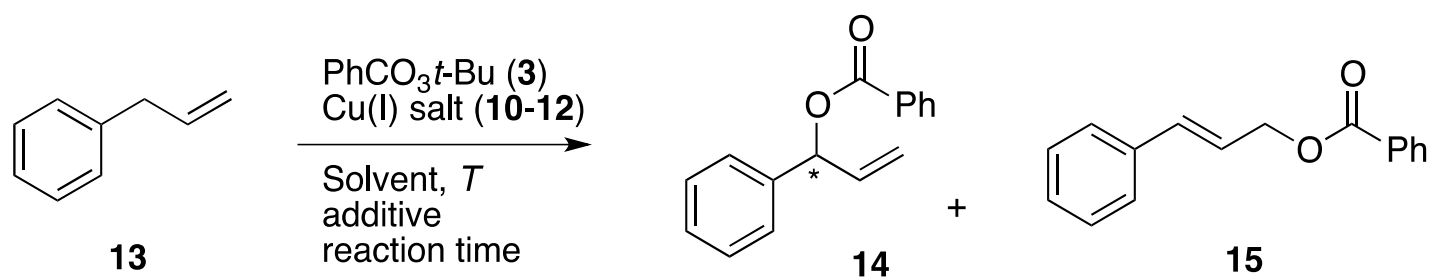

\begin{tabular}{|c|c|c|c|c|c|c|c|c|}
\hline Entry & $\begin{array}{l}\mathrm{Cu}(\mathrm{l}) \text { Salt } \\
\text { (mol\%) }\end{array}$ & Solvent & Additive $^{b}$ & $\mathrm{~T},{ }^{\circ} \mathrm{C}$ & Reaction time & Yield, \% & Ee, \% (config) & $14: 15$ \\
\hline 1 & $(R)-10(5)$ & $\mathrm{Me}_{2} \mathrm{CO}$ & - & 50 & $4 d$ & 18 & $<5$ & $>25: 1$ \\
\hline 2 & $(S)-11(5)$ & $\mathrm{Me}_{2} \mathrm{CO}$ & - & 50 & $4 d$ & 26 & $<5$ & $>25: 1$ \\
\hline 3 & $(S)-11(5)$ & $\mathrm{Me}_{2} \mathrm{CO}$ & $\mathrm{PhNHNH}_{2}$ & r.t. & $2 \mathrm{~d}$ & 71 & $<5$ & $20: 1$ \\
\hline 4 & $(S)-12(5)$ & $\mathrm{Me}_{2} \mathrm{CO}$ & - & 50 & $7 d$ & 37 & $17(S)$ & $>25: 1$ \\
\hline 5 & $(R)-12(5)$ & $\mathrm{Me}_{2} \mathrm{CO}$ & - & 50 & $4 d$ & 60 & $18(R)$ & $20: 1$ \\
\hline 6 & $(R)-12(5)$ & $\mathrm{Me}_{2} \mathrm{CO}$ & $\mathrm{PhNHNH}_{2}$ & 50 & $2 \mathrm{~d}$ & 89 & $25(R)$ & $20: 1$ \\
\hline 7 & $(R)-12(5)^{c}$ & $\mathrm{Me}_{2} \mathrm{CO}$ & $\mathrm{PhNHNH}_{2}$ & 50 & $2 \mathrm{~d}$ & 56 & $<5$ & $20: 1$ \\
\hline 8 & $(S)-12(2)$ & $\mathrm{Me}_{2} \mathrm{CO}$ & $\mathrm{PhNHNH}_{2}$ & r.t. & $3 d$ & 10 & $10(S)$ & $20: 1$ \\
\hline 9 & $(R)-12(5)$ & DCE & $\mathrm{PhNHNH}_{2}$ & 50 & $4 d$ & 97 & $<5$ & $>25: 1$ \\
\hline 10 & $(R)-12(5)$ & $c-\mathrm{C}_{6} \mathrm{H}_{12}$ & $\mathrm{PhNHNH}_{2}$ & 50 & $4 \mathrm{~d}$ & 87 & $6(R)$ & $>25: 1$ \\
\hline 11 & $(R)-12(5)$ & $\mathrm{CH}_{3} \mathrm{CN}$ & - & 50 & $7 d$ & 91 & $<5$ & $>25: 1$ \\
\hline 12 & $(R)-12(1)$ & $\mathrm{CH}_{3} \mathrm{CN}$ & - & 50 & $7 d$ & 60 & $<5$ & $>25: 1$ \\
\hline
\end{tabular}

${ }^{a}$ Unless stated otherwise, the reactions were carried out on a $5 \mathrm{mmol}$ scale, in solvent $(1.0 \mathrm{~mL})$ using tert-butyl peroxybenzoate 3 as the oxidant and a 5 -fold excess of allylbenzene $13 ;{ }^{b} 5$ mol\%; ${ }^{c}$ catalyst was made in situ by stirring a mixture of $\left(\mathrm{Cu}(\mathrm{OTf}){ }_{2}(5 \mathrm{~mol} \%)\right.$ and $(R)-9$ in acetone for $5 \mathrm{~min}$ prior to addition of other reactants.

Influence of solvent on the outcome of the reaction was briefly investigated. In dichloroethane (entry 9) and in cyclohexane (entry 10), using phenylhydrazine as a reducing reagent, at $50^{\circ} \mathrm{C}$ the reaction reached completion in 4 days to afford pure branched isomer 14 in high yield ( 97 and $87 \%$, respectively) but in almost completely racemic form. In acetonitrile, the allylic oxidation was investigated using 5 or $1 \mathrm{~mol} \%$ catalyst loading (entries 11 and 12, respectively). In the absence of the reducing agent, the reaction was slower compared to the same experiment in acetone and, despite high regioselectivity in favour of the branched isomer $\mathbf{1 4}$, the enantioselectivity remained negligible.

Mechanistic investigations [5] of the KharaschSosnovsky reaction suggested that the reaction commences with the oxidation of peroxybenzoate
3 by $\mathrm{Cu}(\mathrm{I})$ to give $\mathrm{Cu}(\mathrm{II})$ benzoate $\mathbf{A}$ and tert-butoxy radical (Scheme 3). The latter then abstracts hydrogen form the alkene, e.g. 13, and the resulting allylic radical $\mathbf{B}$ combines with benzoate $\mathbf{A}$ to give the $\mathrm{Cu}(\mathrm{III})$ intermediate $\mathbf{C}$, which upon reductive elimination affords allylic benzoate 14. An alternative non-radical route, in which hydrogen abstraction takes place in an intramolecular fashion converging to intermediate $\mathbf{C}$, was also proposed based on computational data [7].

According to the proposed reaction mechanism, oxidation of allylbenzene and $\beta$-methylstyrene should proceed either through the common allylic intermediate B [5] or involve the common $\eta^{3}$-allylcopper complex resulting from the fast haptotropic rearrangement in C [7]. Therefore, we next examined allylic oxidation of both isomers of $\beta$-methylstyrene, $(E)-16$ and $(Z)-16$ 
(Scheme 4). In acetone at $50^{\circ} \mathrm{C}$, with catalyst $(R)-12$ (5 mol\% loading) and phenylhydrazine ( $5 \mathrm{~mol} \%$ ) as reducing reagent, the reactions went to completion in 5 days but, rather unexpectedly, furnished racemic trans-epoxide $\mathbf{1 7}$ as the major product ( $70 \%$ from $(E)-\mathbf{1 6}$ and $80 \%$ from $(Z)-16)$. Allylic oxidation products were formed in minor quantities. Nonetheless, in both cases formation of only branched isomer $\mathbf{1 4}$ was observed. Furthermore, the ester $(R)$-14 resulting from $(E)-\mathbf{1 6}$ showed the highest enantioselectivity obtained for the whole series ( $35 \%$ ee).This result is comparable with recent literature results reported for this reaction [37].

In conclusion, application of $\mathrm{Cu}(\mathrm{I})$ salts derived from axially chiral phosphoric acids in asymmetric Kharasch-Sosnovsky oxidation of acyclic alkenes has been investigated. Under the optimized conditions, the reaction proceeded in good yield and exhibited high regioselectivity towards the branched ester. Despite the low enantioselectivity obtained to-date, the chiral counterion strategy produced promising leads which warrant further investigation.

\section{Experimental part}

\section{A typical procedure for allylic oxidation.}

Copper (I) salt (20.3 mg, $0.025 \mathrm{mmol}, 5 \mathrm{~mol} \%$ ) was weighed in a reaction tube and was evacuated and backfilled with $\mathrm{N}_{2}$. The reaction vessel was charged with acetone $(1 \mathrm{~mL})$ that had been previoulsy deoxygenated by purging with a stream of nitrogen for $20 \mathrm{~min}$. This was followed by addition via syringe of phenylhydrazine (3 $\mu \mathrm{L}, 0.025 \mathrm{mmol}, 5 \mathrm{~mol} \%$ ) and allylbenzene $(0.33 \mathrm{~mL}$, $2.5 \mathrm{mmol}, 5$ equiv.). The reaction mixture was stirred for $30 \mathrm{~min}$, then tert-butyl peroxybenzoate $(0.1 \mathrm{~mL}, 0.5 \mathrm{mmol}$, 1 equiv.) was added via syringe and the resulting mixture was stirred at the temperature specified in Table 1 until the oxidant was fully consumed, according to TLC. The solvent was evaporated and the residue was dissolved in dichloromethane $(15 \mathrm{~mL})$. The resulting solution was washed successively with saturated aqueous $\mathrm{KHCO}_{3}$ $(15 \mathrm{~mL})$, brine $(15 \mathrm{~mL})$ and water $(15 \mathrm{~mL})$ and dried over $\mathrm{MgSO}_{4}$. The solvent was removed under reduced pressure
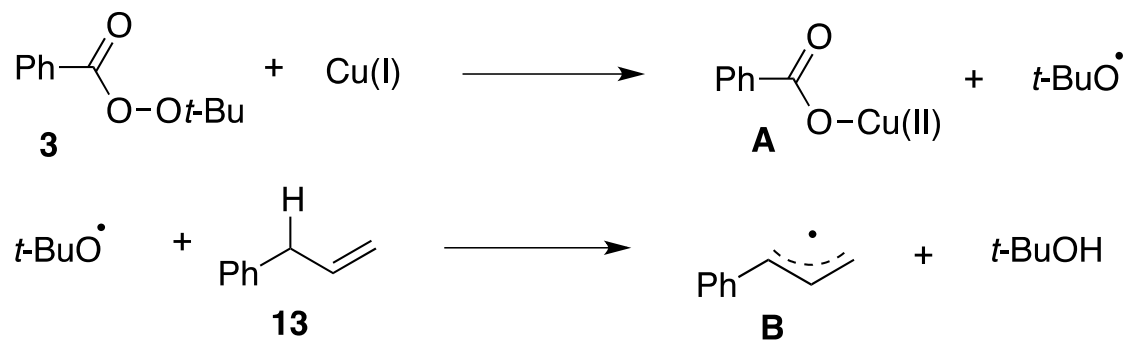

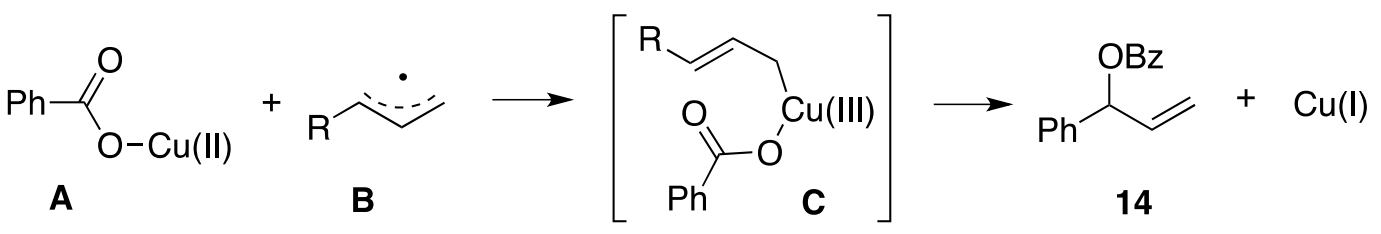

Scheme 3<smiles>CC=Cc1ccccc1</smiles>

$(E)-16$

or<smiles>C/C=C\c1ccccc1</smiles>

$(Z)-16$
$\mathrm{PhCO}_{3} t-\mathrm{Bu}(3)$

$\mathrm{Cu}(\mathrm{I})$ salt (12)

(5 mol\%)

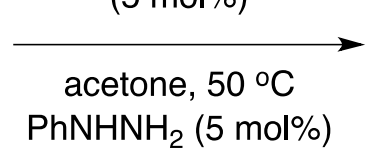

$5 \mathrm{~d}$<smiles>C=CC(OC(=O)c1ccccc1)c1ccccc1</smiles>

$(R)-14$<smiles>CC1(C)OC1c1ccccc1</smiles>

17

From $(E)-1635 \%$ ee; $14 / 17=3: 7$

From $(Z)-1620 \%$ ee; $14 / 17=1: 4$ 
and the residue was purified by column chromatography on silica gel $(20 \times 150 \mathrm{~mm})$ eluting with a 98:2 mixture of light petroleum/ethyl acetate.

\section{1-Phenylallyl benzoate (14)}

1H NMR (400 MHz, CDCl3) $\delta$ : 5.20 (dt, $J=10.4,1.2 \mathrm{~Hz}$, $1 \mathrm{H}), 5.31(\mathrm{dt}, J=17.2,1.2 \mathrm{~Hz}, 1 \mathrm{H}), 6.04(\mathrm{~m}, 1 \mathrm{H}), 6.43(\mathrm{~d}, J=6$ $\mathrm{Hz}, 1 \mathrm{H}), 7.20-7.47$ (m, 8H), $8.02(\mathrm{~d}, J=8 \mathrm{~Hz}, 2 \mathrm{H}) .13 \mathrm{C}$ NMR (100 MHz, CDCl3) 8: 76.7 (d), 117.1 (t), 127.2 (d), 128.2 (d), 128.4 (d), 128.6 (d), 129.7 (d), 129.9 (s), 130.3 (s), 133.1 (d), 136.3 (d), 139.0 (s), 165.5 (s). IR: $u$ 3066, 30332, 1719, 1451, 1266, 1107, 1069, 1025, 711, $699 \mathrm{~cm}^{-1}$; in agreement with literature data [43].

HPLC: Chiralpak IA-3; 99.5:0.5 hexane:iPrOH: $8.81 \mathrm{~min}$., major $(R)$-enantiomer; $12.67 \mathrm{~min}$., minor $(S)$-enantiomer.

\section{1-Phenylallyl benzoate (racemic)}

Benzaldehyde ( $2 \mathrm{mmol}, 0.2 \mathrm{~mL}, 1$ eq.) and freshly distilled THF ( $5 \mathrm{~mL}$ ) were placed in a $25 \mathrm{~mL}$ oven-dried RBF under $\mathrm{N}_{2}$ atmosphere. The solution was cooled to $0^{\circ} \mathrm{C}$. A solution of vinyl magnesium bromide $1 \mathrm{M}$ in THF ( $2 \mathrm{mmol}, 2 \mathrm{~mL}$ ) was added dropwise and the resulting mixture was stirred at that temperature for 1.5 hours. After that time, pyridine (4 mmol, $0.32 \mathrm{~mL}, 2$ equiv.) and benzoyl chloride $(2.6 \mathrm{mmol}$, $0.30 \mathrm{~mL}, 1.3$ equiv.) were added dropwise via syringe and the mixture was allowed to warm up to room temperature and the reaction was stirred overnight. The suspension was quenched with $5 \mathrm{~mL} \mathrm{HCl} 1 \mathrm{M}$. The resulting solution was washed with saturated aqueous $\mathrm{NaHCO}_{3}$. Organic phase was dried over $\mathrm{MgSO}_{4}$ and volatiles were removed under reduced pressure. The residue mixture was purified by column chromatography ( $20 \times 150 \mathrm{~mm}$ ) eluting with 98:2 light petroleum/ethyl acetate to afford the title compound as a colorless oil.

\section{Cinnamyl benzoate (15)}

$25 \mathrm{~mL}$ RBF was evacuated and backfilled with $\mathrm{N}_{2}$ and charged with cinnamyl alcohol $(3 \mathrm{mmol}, 402.5 \mathrm{mg}, 1$ equiv.) and freshly distilled THF $(5 \mathrm{~mL})$. Pyridine $(6$ mmol, $0.485 \mathrm{~mL}, 2$ equiv.) was added dropwise followed by benzoyl chloride ( $4 \mathrm{mmol}, 0.46 \mathrm{~mL}, 1.3$ equiv.) at room temperature. The reaction mixture was allowed to stir for 1.5 hours. After that time, the mixture was quenched with $5 \mathrm{~mL} \mathrm{HCl} 1 \mathrm{M}$ and washed with $5 \mathrm{~mL}$ of a saturated aqueous $\mathrm{NaHCO}_{3}$. The organic phase was dried over $\mathrm{MgSO}_{4}$ and solvent was removed under reduced pressure. The residue was purified by column chromatography (35 x $120 \mathrm{~mm}$ ) eluting with a 95:5 mixture of light petroleum/ ethyl acetate, to afford the title compound as a colorless oil (548 mg, 77\%).
1H NMR (400 MHz, CDCl3) $\delta: 5.03$ (dd, $J=6.4,1.2 \mathrm{~Hz}$, $2 \mathrm{H}), 6.45(\mathrm{dt}, J=16,6.4 \mathrm{~Hz}, 1 \mathrm{H}), 6.78(\mathrm{~d}, J=16 \mathrm{~Hz}, 1 \mathrm{H}), 7.28$ $7.32(\mathrm{~m}, 1 \mathrm{H}), 7.36$ (t, $J=5.2 \mathrm{~Hz}, 2 \mathrm{H}), 7.45-7.51(\mathrm{~m}, 4 \mathrm{H}), 7.60$ (t, $J=6.8 \mathrm{~Hz}, 1 \mathrm{H}), 8.13$ (d, $J=8.2 \mathrm{~Hz}, 2 \mathrm{H}) .13 \mathrm{C}$ NMR (100 MHz, CDCl3) $8: 65.7$ (t), 1233 (d), 126.7 (d), 128.1 (d), 128.4 (d), 128.6 (d), 129.7 (d), 130.2 (s), 133.0 (d), 134.3 (d), 136.2 (s), 166.4 (s). IR: $v$ 3060, 3027, 2941, 1718, 1601, 1495, 1450, $1208,1175,1116,965,746,710,691 \mathrm{~cm}^{-1}$; in agreement with literature data [44].

HPLC: Chiralpak IA-3; 99.5:0.5 hexane:iPrOH: $15.51 \mathrm{~min}$.

Acknowledgement: We thank Loughborough University for the studentship to C. A. I. P. and other financial support.

\section{References}

[1] Kharasch M. S., Sosnovsky G. The reactions of t-butyl perbenzoate and olefins - a stereospecific reaction. J. Am. Chem. Soc., 1958, 80, 756-756.

[2] Kharasch, M. S.; Sosnovsky, G. Reactions of t-butyl peresters. I. The reaction of peresters with olefins. J. Am. Chem. Soc., 1959, 81, 5819-5824.

[3] Sosnovsky G., Lawesson S. 0. The peroxyester reaction. Angew. Chem. Int. Ed., 1964, 3, 269-276.

[4] Blanksby S. J., Ellison G. B. Bond dissociation energies of organic molecules. Acc. Chem. Res., 2003, 36, 255-263.

[5] Beckwith A. L. J., Zavitsas A. A. Allylic oxidations by peroxy esters catalyzed by copper salts. The potential for stereoselective syntheses. J. Am. Chem. Soc., 1986, 108, 8230-8234.

[6] Smith K., Hupp C. D., Allen K. L., Slough G. A. Catalytic allylic amination versus allylic oxidation: a mechanistic dichotomy. Organometallics, 2005, 24, 1747-1755.

[7] Mayoral J. A., Rodríguez-Rodríguez S., Salvatella L. Theoretical insights into enantioselective catalysis: the mechanism of the Kharasch-Sosnovsky reaction. Chem. Eur. J., 2008, 14, 9274-9285.

[8] Kochi J. K. The mechanism of the copper salt catalysed reactions of peroxides. Tetrahedron, 1962, 18, 483-497.

[9] Kochi J. K. Oxidation of allylic radicals by electron transfer: effect of complex copper salts. J. Am. Chem. Soc., 1962, 84, 3271-3277.

[10] Gephart R. T., III, McMullin C. L., Sapiezynski N. G., Jang E. S., Aguila M. J. B., Cundari T. R., Warren T. H. Reaction of $\mathrm{Cu}^{\prime}$ with

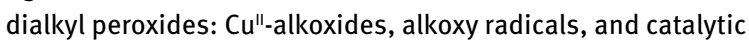
C-H etherification. J. Am. Chem. Soc., 2012, 134, 17350-17353.

[11] Jang E. S., McMullin C. L., Käß M., Meyer K., Cundari T. R., Warren T. H. Copper(II) anilides in $\mathrm{sp}^{3} \mathrm{C}-\mathrm{H}$ amination. J. Am. Chem. Soc., 2014, 136, 10930-10940.

[12] Tran B. L., Li B., Driess M., Hartwig J. F. Copper-catalyzed intermolecular amidation and imidation of unactivated alkanes. J. Am. Chem. Soc., 2014, 136, 2555-2563.

[13] Denney D. B., Napier R., Cammarata A. A convenient method for the preparation of some optically active allylic alcohols. J. Org. Chem., 1965, 30, 3151-3153.

[14] Muzart J. Enantioselective copper-catalyzed allylic acetoxylation of cyclohexene. J. Mol. Catal., 1991, 64, 381-384. 
[15] Gokhale A. S., Minidis A., Pfaltz A. Enantioselective allylic oxidation catalyzed by chiral bisoxazoline-copper complexes. Tetrahedron Lett., 1995, 36, 1831-1834.

[16] Andrus M. B., Argade A. B., Chen X., Pamment M. G. The asymmetric Kharasch reaction. catalytic enantioselective allylic acyloxylation of olefins with chiral copper $(I)$ complexes and tert-butyl perbenzoate. Tetrahedron Lett., 1995, 36, 2945-2948.

[17] Andrus M. B., Chen X. Catalytic enantioselective allylic oxidation of olefins with copper(I) catalysts and new perester oxidants. Tetrahedron, 1997, 53, 16229-16240.

[18] Fahrni C. J. Allylic oxidation catalyzed by chiral dinuclear copper complexes. Tetrahedron, 1998, 54, 5465-5470.

[19] Schulz M., Kluge R., Gelalcha F. G. Asymmetric peroxidation of prochiral allylic and benzylic compounds with tert-butyl hydroperoxide and chiral bisoxazoline-copper complexes. Tetrahedron: Asymmetry, 1998, 9, 4341-4360.

[20] Brunel J.-M., Legrand O., Buono G. Recent advances in asymmetric copper allylic oxidation of olefins. C.R. Acad. Sci. II C, 1999, 2, 19-23.

[21] Eames J., Watkinson M. Catalytic allylic oxidation of alkenes using an asymmetric Kharasch-Sosnovsky reaction. Angew. Chem. Int. Ed., 2001, 40, 3567-3571.

[22] Andrus M. B., Lashley J. C. Copper catalyzed allylic oxidation with peresters. Tetrahedron, 2002, 58, 845-866.

[23] Malkov A. V., Bella M., Langer V., Kočovský P. PINDY: a novel, pinene-derived bipyridine ligand and its application in asymmetric, copper(I)-catalyzed allylic oxidation. Org. Lett. 2000, 2, 3047-3049.

[24] Malkov A. V., Pernazza D., Bell M., Bella M., Massa A., Teplý F., Meghani P., Kočovský P. Synthesis of new chiral 2,2'-bipyridine ligands and their application in copper-catalyzed asymmetric allylic oxidation and cyclopropanation. J. Org. Chem., 2003, 68, 4727-4742.

[25] Sekar G., DattaGupta A., Singh V. K. Asymmetric Kharasch reaction: catalytic enantioselective allylic oxidation of olefins using chiral pyridine bis(diphenyloxazoline)-copper complexes and tert-butyl perbenzoate. J. Org. Chem., 1998, 63, 2961-2967.

[26] Andrus M. B., Zhou Z. Highly enantioselective copperbisoxazoline-catalyzed allylic oxidation of cyclic olefins with tert-butyl p-nitroperbenzoate. J. Am. Chem. Soc., 2002, 124, 8806-8807.

[27] Ginotra S. K., Singh V. K. Studies on enantioselective allylic oxidation of olefins using peresters catalyzed by $\mathrm{Cu}(\mathrm{I})$ complexes of chiral pybox ligands. Org. Biomol. Chem., 2006, 4, 4370-4374.

[28] Ginotra S. K., Singh V. K. Enantioselective oxidation of olefins catalyzed by chiral copper bis(oxazolinyl)pyridine complexes: a reassessment. Tetrahedron 2006, 62, 3573-3581.

[29] Kohmura Y., Katsuki T. Asymmetric allylic oxidation of cycloalkenes using a tridentate tris(oxazoline) ligand as a chiral auxiliary. Tetrahedron Lett., 2000, 41, 3941-3945.

[30] García-Cabeza A. L., Marín-Barrios R., Moreno-Dorado F. J., Ortega M. J., Massanet G. M., Guerra F. M. Allylic oxidation of alkenes catalyzed by a copper-aluminum mixed oxide. Org. Lett., 2014, 16, 1598-1601.
[31] Samadi S., Nazari S., Arvinnezhad H., Jadidi K., Notash B. A significant improvement in enantioselectivity, yield, and reactivity for the copper-bi-o-tolyl bisoxazoline-catalyzed asymmetric allylic oxidation of cyclic olefins using recoverable SBA-15 mesoporous silica material. Tetrahedron, 2013, 69, 6679-6686.

[32] Aldea L., García J. I., Mayoral J. A. Multiphase enantioselective Kharasch-Sosnovsky allylic oxidation based on neoteric solvents and copper complexes of ditopic ligands. Dalton Trans., 2012, 41, 8285-8285.

[33] Marín-Barrios R., Guerra F. M., García-Cabeza A. L., MorenoDorado F. J., Massanet G. M. Multivariate optimization of the Kharasch-Sosnovsky allylic oxidation of olefins. Tetrahedron, 2012, 68, 1105-1108.

[34] Samadi S., Jadidi K., Notash B. Chiral bisoxazoline ligands with a biphenyl backbone: development and application in catalytic asymmetric allylic oxidation of cycloolefins. Tetrahedron: Asymmetry, 2013, 24, 269-277.

[35] Aldea L., Delso I., Hager M., Glos M., García J. I., Mayoral J. A., Reiser O. A Reusable enantioselective catalytic system for the Kharasch-Sosnovsky allylic oxidation of alkenes based on a ditopic azabis(oxazoline) ligand. Tetrahedron, 2012, 68, 3417-3422.

[36] Kawasaki K.-I., Katsuki T. Enantioselective allylic oxidation of cycloalkenes by using Cu(II)-tris(oxazoline) complex as a catalyst. Tetrahedron, 1997, 53, 6337-6350.

[37] Zhang B., Zhu S.-F., Zhou Q.-L. Copper-catalyzed enantioselective allylic oxidation of acyclic olefins. Tetrahedron Lett. 2013, 54, 2665-2668.

[38] Mayer S., List B. Asymmetric counteranion-directed catalysis. Angew. Chem. Int. Ed., 2006, 45, 4193-4195.

[39] Hamilton G. L., Kang E. J., Mba M., Toste F. D. A powerful chiral counterion strategy for asymmetric transition metal catalysis. Science, 2007, 317, 496-499.

[40] Phipps R. J., Hamilton G. L., Toste F. D. The progression of chiral anions from concepts to applications in asymmetric catalysis. Nat. Chem., 2012, 4, 603-614.

[41] Akiyama T., Itoh J., Fuchibe K. Recent progress in chiral Brønsted acid catalysis. Adv. Synth. Catal., 2006, 348, 999-1010.

[42] Zamfir A., Schenker S., Freund M., Tsogoeva S. B. Chiral BINOL-derived phosphoric acids: privileged Brønsted acid organocatalysts for $\mathrm{C}-\mathrm{C}$ bond formation reactions. Org. Biomol. Chem., 2010, 8, 5262-6276.

[43] Kanbayashi N., Onitsuka K. Enantioselective synthesis of allylic esters via asymmetric allylic substitution with metal carboxylates using planar-chiral cyclopentadienyl ruthenium catalysts. J. Am. Chem. Soc., 2010, 132, 1206-1207.

[44] Liu G., Zheng L., Shao M., Zhang H., Qiao W., Wang X., Liu B., Zhao H., Wang J. A six-coordinated cationic ruthenium carbyne complex with liable pyridine ligands: synthesis, structure, catalytic investigation, and DFT study on initiation mechanism. Tetrahedron, 2014, 70, 4718-4725

Supplemental Material: The online version of this article (DOI: 10.1515/asorg-2015-0005) offers supplementary material. 